treatment option for pain relief, besides treatment with oral non-steroidal anti-inflammatory (NSAIDs) before starter biotechnological treatment. However, there are few studies to evaluate efficacy of this technique with a small number of patients and a short follow-up. Ultrasonography has been used as a valuable option to guide this technique.

Objectives: To evaluate the efficacy and safety of ultrasound-guided injections of sacroiliac joints (SIJs) in patients with sacroiliitis using clinical and laboratory outcomes at baseline and at $4-6^{\text {th }}$ weeks.

Methods: This study involved patients with axSpA with acute sacroiliitis, $\geq 18$ and $\leq 65$ years old, with body mass index $(\mathrm{BMI})<30 \mathrm{~kg} / \mathrm{m}^{2}$ attending the Rheumatology Outpatient Clinic, which had been poorly controlled (ASDAS>2.1) by conventional therapy (physiotherapy, NSAIDs at maximum tolerated dosing during $\geq$ 4 weeks). Sociodemographic, clinical (disease duration, BMI, BASDAI, BASFI, ASDAS) and laboratory (CRP) data was collected from the medical records at baseline and at $4-6^{\text {th }}$ weeks.

Statistical analyses were conducted using SPSS version 25. Continuous variables were described with mean/median \pm standard deviation (SD).

SIJs injection was performed, under ultrasound guidance, using standard procedures with $2 \mathrm{~mL}$ of lidocaine $1 \%$ and $40 \mathrm{mg}$ of methylprednisolone, with a 22 -gauge needle. The procedure was performed by the same operator. Written informed consents were obtained from all patients.

Results: We performed eleven sacroiliac injection in eleven consecutive patients (one procedure per patient). Nine patients (81.8\%) were female, mean age $( \pm S D)$ of $40.6( \pm 9.4)$ years, median disease duration $( \pm S D)$ of $0.9( \pm 6.2)$ years and median $\mathrm{BMI}( \pm \mathrm{SD})$ of $24.2( \pm 3.3)$. Eight patients $(72.7 \%)$ had $\mathrm{Nr}$-axSpA. All patients were non-responders to NSAIDs.

At $4-6^{\text {th }}$ weeks there was a decreased in median $( \pm S D)$ BASDAI $(5.4 \pm 1.9$ vs $4.1 \pm 1.9)$, BASFI $(4.2 \pm 1.4$ vs $3.5 \pm 2.3)$ and ASDAS (3.2 \pm 0.8 vs $2.2 \pm 0.6)$ indexes. Conclusion: As previous studies demonstrated, this technique seems to be safe and quite effective.

Our goal is to increase the number of patients undergoing this technique and have a longer follow up to evaluate its efficacy. The study has several limitations: the mid- and long-term effects should be evaluated in the future based on the results of the short-term effects and the study was not conducted as a double-blinded, controlled study.

References:

[1] van der Heijde D, Burgos-Vargas R, Ramiro S.,et al. ASAS/EULAR recommendations for the management of ankylosing spondylitis. Ann Rheum Dis 2017; 76:978-991

[2] Maugars Y, Mathis C, Vilon P, Prost A. Corticosteroid injection of the sacroiliac joint in patients with seronegative spondylarthropathy. Arthritis Rheum 1992; 35:564-8

[3] Pekkafahli MZ, Kiralp MZ, Basekim CC et al. Sacroiliac joint injections performed with sonographic guidance. J Ultrasound Med 2003;22:553-9

[4] Klauser A, De Zordo T, Feuchtner G et al. Feasibility of ultrasound-guided sacroiliac joint injection considering sonoanatomic landmarks at two different levels in cadavers and patients. Arthritis Rheum 2008; 59:1618-1624.

Disclosure of Interests: Ana Rita Cunha: None declared, Carolina Mazeda: None declared, Renata Aguiar: None declared, Anabela Barcelos Speakers bureau: Bene, Eli-Lilly, Pfizer, MSD, Novartis

DOI: 10.1136/annrheumdis-2020-eular.6133

\section{AB0643 DRUG SURVIVAL OF SECUKINUMAB IN A SPONDYLOARTHRITIS COHORT. A 24 MONTHS MULTICENTRIC STUDY}

P. Navarro Alonso ${ }^{1}$, Á. García Martos ${ }^{2}$, A. Castilla ${ }^{3}$, L. González ${ }^{2}$, M. D. C. Ortega ${ }^{4}$, C. Arconada ${ }^{4}$, A. Prada-Ojeda ${ }^{5}$, L. Sala Icardo ${ }^{5}$, L. Barrio Nogal ${ }^{5}$, E. M. Andres ${ }^{6}$ A. Diaz Oca ${ }^{1} .{ }^{1} H U$ Fuenlabrada, Madrid, Spain; ${ }^{2} H U$ del Tajo, Aranjuez, Spain; ${ }^{3} \mathrm{HU}$ La Paz, Madrid, Spain; ${ }^{4} \mathrm{HU}$ Infanta Elena, Valdemoro, Spain; ${ }^{5}$ HU Torrejon, Torrejon de Ardoz, Spain; ${ }^{6}$ Universidad Rey Juan Carlos, Madrid, Spain

Background: Secukinumab inhibits the interaction between Interleukin 17A (IL-17A) and its receptor. Clinical trials have demonstrated good data in efficacy and safety in patients with spondyloarthritis (SpA) as first biological choice or inadecuate response to other biological in SpA. However there is few evidence in real clinical practice.

Objectives: Evaluate the drug survival in a real clínical practice, as an indirect way to show the efficacy and security of Secukinumab at 24 months

Methods: A multicentric observational, longitudinal, retrospective study of 24 months conducted in five Madrid hospitals (Spain). Patients older than 18 years treated with Secukinumab which fullfilled ASAS criteria for SpA and/ or modified New York criteria for ankylosing spondylitis (AS) and/or CASPAR criteria for psoriatic arthritis (PsA) were included. For evaluation of the drug survival, dates from starting until closing date or definite withdrawal of the treatment were determined. Kaplan-Meier function was used to estimate the drug survival and Wilcoxon test for the comparison of the survival rate between the different diagnoses, because of the survival curves did not reach the median

Results: A total of 71 patients were included. The mean age was 50.26 ys (SD 11.01), 57.75\% women. 35 patients fullfilled classification criteria for PsA ant 36 fullfilled classification criteria for axSpA. 22 patients were naïve for biologic therapies and 49 patients had an inadecuate response to TNFi. 13 patients discontinued Secukinumab before the closing date, the main reason for the interruption was secondary failure $(n=6)$, and primary failure $(n=2)$. Secukinumab surviva rate was $81.95 \%$ up to 24 months in this cohort. The median of survival was 2.36 years (IC: 1.79-2.84). There were no significant differences about the drug survival related to diagnosis $(p=0.976)$. The safety data were similar to those described in clinical trials.

Conclusion: Secukinumab is an effective and safe treatment for the management of espondiloarthritis regardless of the subtypes, with a high survival rate. In this study naive patients show similar data obtained in clinical trials. In this cohort of patients, those who initiated secukinumab after failure to TNFi, showed a greater secukinumab survival than the data provided in clinical trials

Disclosure of Interests: None declared

DOI: 10.1136/annrheumdis-2020-eular.3666

\section{AB0644 \\ ULTRASOUND GUIDED EPIDURAL INJECTION IN RADIOGRAPHIC AXIAL SPA PATIENTS WITH LIMITED SPINE MOBILITY: A PROSPECTIVE PILOT RANDOMIZED CONTROLLED TRIAL}

A. Hamed ${ }^{1}$, A. Radwan ${ }^{2}$, O. Sayed ${ }^{3}$, A. Elsaman ${ }^{4} .{ }^{1}$ Minya University, Minya, Egypt; ${ }^{2}$ Sohag University Hospital, Rheumatology and Rehabilitation

Department, Sohag, Egypt; ${ }^{3}$ Minya University, Rheumatology and Rehabilitation Department, Minya, Egypt; ${ }^{4}$ Sohag University Hospital, Rheumatology and Rehabilitation, Sohag, Egypt

Background: Ankylosing Spondylitis (AS) is a systemic inflammatory disease of unknown origin. It affects mainly males. Chronic inflammatory back pain is the commonest presenting symptom and regularly develops between 20 and 40 years age. AS can likewise, have extra-articular manifestations. These manifestations commonly develop after the onset of axial symptoms but hardly can precede them. Even though AS is a systemic disease, the presenting symptoms, treatment, and morbidity are largely dependent on spine affection. Epidural injections for managing chronic low back pain are one of the most frequently performed interventions in the United States. Friedly et al reported administration of epidural injections in $36 \%$ of patients with axial low back pain. However, there is no clinical evidence for the use of epidural injections in axial SPA and most recommendations are limited to radicular pain with disc herniation. The evidence for caudal epidural injections is Level I in managing pain secondary to disc herniation and radiculitis. To our best of knowledge, this is the first study evaluating the role of caudal epidural steroid and lidocaine injections in managing pain and function of the spine in radiographic axial SPA.

Objectives: To evaluate the significance of caudal epidural injections in controlling pain and spinal stiffness in radiographic axial SPA

Methods: In our study 32 Patients were included. They were randomly doled out into 2 equivalent groups; Group I received caudal epidural injections ultrasound guided with 1\% lidocaine hydrochloride (xylocaine, AstraZeneca) $9 \mathrm{~mL}$ mixed with $1 \mathrm{~mL}$ of triamcinolone 40 milligrams (Kenacort, Bristol Myers Squip), whereas Group II did not receive. Both groups were matched regarding age, sex and disease duration (table) and both were under treatment with anti TNF and NSAIDs with or without sDMARDs. All participants fulfilled the ASAS criteria for radiographic axial SPA. Outcomes measures included visual Analogue Scale (VAS), and ASDAS score with assessment at baseline, 2 weeks and 8 weeks post-treatment. Significant pain relief was defined as $50 \%$ or more or no pain. ASDAS improvement is considered when the score reduction $\geq 1.1$.

Results: There was a significant difference between both groups regarding pain (Figure 1) and ASDAS scores (Figure 2) in favor of group I. This effect was maximum after 2 weeks interval. More than two thirds of the cases $(68.8 \%)$ had significant pain relief among group 1, compared to only $18.8 \%$ among group 2. Despite the decline of this effect after 8 weeks, still the difference significant between both groups. Shorter disease duration and older age of onset were associated with better outcomes among group 1 but not group 2. However, these correlations were non-significant. 


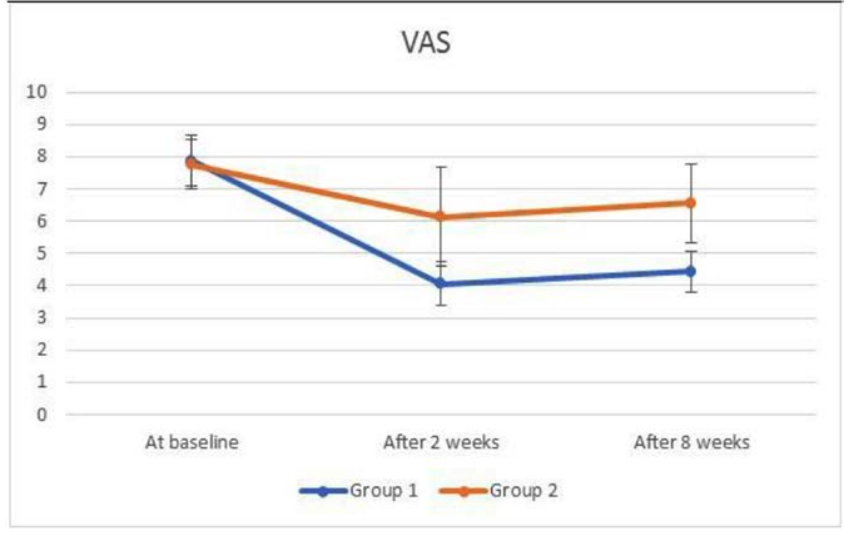

Figure 1. Change of VAS between the two groups.

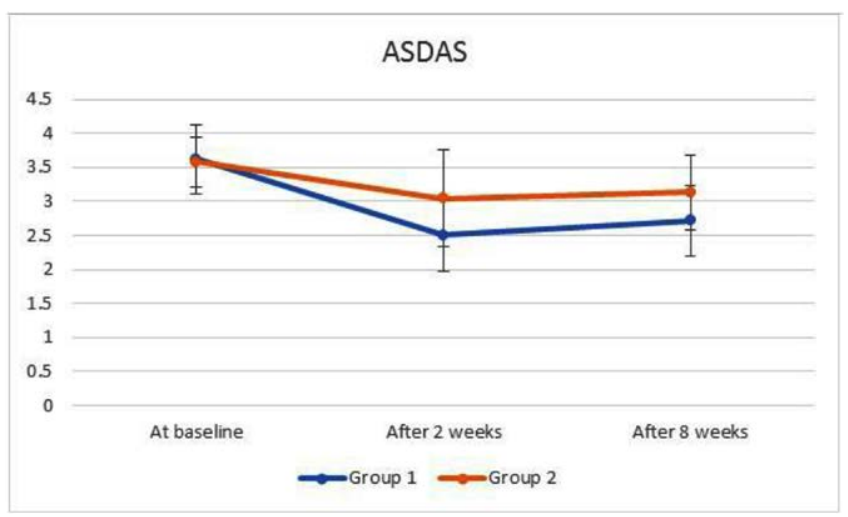

Figure 2. Change of VAS between the two groups.

Conclusion: Caudal epidural injection is cheap, effective and practical technique in controlling pain and stiffness of the spine in radiographic axial SPA with acceptable complications and relatively sustained effect. Studies including bigger number of participants and longer span of follow up still required.

Table. Comparison between the two groups as regards demographic and outcome data

\begin{tabular}{lcccc}
\hline Item & & Group 1 & Group 2 & P value \\
\hline Age & Male & $40.31 \pm 4.54$ & $38.88 \pm 5.44$ & 0.423 \\
Sex & Female & $10(62.5 \%)$ & $9(56.2 \%)$ & 0.719 \\
& (in years) & $3.13 .5 \%)$ & $7(43.8 \%)$ & \\
Disease duration & At baseline & $7.88 \pm 0.81$ & $3.22 \pm 1.24$ & 0.847 \\
VAS & After 2 weeks & $4.06 \pm 0.68$ & $6.13 \pm 0.77$ & 0.658 \\
& After 8 weeks & $4.44 \pm 0.63$ & $6.56 \pm 1.21$ & $<0.001$ \\
& \% improved at 2 weeks & $11(68.8 \%)$ & $3(18.8 \%)$ & $\mathbf{0 . 0 0 4}$ \\
& \% improved at 8 weeks & $6(37.5 \%)$ & $2(12.5 \%)$ & 0.102 \\
ASDAS & At baseline & $3.62 \pm 0.51$ & $3.58 \pm 0.37$ & 0.814 \\
& After 2 weeks & $2.50 \pm 0.53$ & $3.04 \pm 0.71$ & $\mathbf{0 . 0 2 0}$ \\
& After 8 weeks & $2.72 \pm 0.52$ & $3.13 \pm 0.55$ & $\mathbf{0 . 0 3 6}$ \\
& \% improved at 2 weeks & $10(62.5 \%)$ & $3(18.8 \%)$ & $\mathbf{0 . 0 1 2}$ \\
& \% improved at 8 weeks & $7(43.8 \%)$ & $2(12.5 \%)$ & 0.057 \\
\hline
\end{tabular}

Acknowledgments: None

Disclosure of Interests: None declared

DOI: 10.1136/annrheumdis-2020-eular.501

\section{AB0645 PREDICTORS OF THE EFFECTIVENESS OF INTRA- ARTICULAR GLUCOCORTICOID INJECTIONS IN RHEUMATIC HIP INVOLVEMENT}

H. Ferjani ${ }^{1}$, L. Ben Ammar ${ }^{1}$, K. Maatallah ${ }^{1}$, D. Ben Nessib ${ }^{1}$, D. Kaffel ${ }^{1}$, W. Hamdi'. 'Kassab Institute, Rheumatology, Tunis, Tunisia

Background: Hip involvement in chronic inflammatory rheumatic diseases is a turning point in the course of the disease because of disability and functional impairment. Total joint replacement surgery rate in spondyloarthritis increased
$40 \%$ despite the use of Disease-modifying anti-rheumatic drugs (DMARD) and biologic treatment. Intra-articular glucocorticoid injection may help prevent hip joint replacement surgery and radiographic progression.

Objectives: This study aimed to determine predictive factors of the steroid injections' efficiency in chronic inflammatory rheumatic diseases with hip involvement.

Methods: This is a retrospective study over a 13-years (2006-2019) that included patients followed for chronic inflammatory rheumatic diseases complicated by hip involvement and underwent intra-articular glucocorticoid injection.

Results: Forty-two patients were enrolled: 32 male $(76,2 \%)$ and 10 women $(23,8 \%)$. The average age was 27 years [6-73] at the time of the steroid injection. Ankylosing spondylitis (AS) was present in $73,8 \%$ of cases (radiographic axial spondylarthritis $90,3 \%$, Psoriatic spondylitis $6,5 \%$ and peripheral enthesitis $3.2 \%$ ) and juvenile idiopathic arthritis (JIA) in $26.2 \%$ of cases (enthesitis-related arthritis $63,6 \%$, oligoarticular JIA 18,2\%, seronegative polyarticular JIA 9,1\% and juvenile psoriatic arthritis $9,1 \%$ ). Active smoking was found in $47.6 \%$ of cases. All patients were on DMARD: NSAIDs (19\%), methotrexate $(42.9 \%)$, salazopyrin $(23.8 \%)$, combination of methotrexate and salazopyrin $(2.4 \%)$ and anti-TNF alpha $(7.1 \%)$.

Hip involvement was bilateral in $81 \%$ of patients. Examination revealed pain and limited hip mobility in all cases. Radiographic forms in AS were: early coxitis $(17,2 \%)$, condensing form $(17,2 \%)$, destructive form $(58,6 \%)$, synostosante $(3,4 \%)$ et combined $(3,4 \%)$. During JIA, hip involvement was destructive in $45.4 \%$ of cases and minimal to moderate in the remaining cases.

Lequesne algofunctional index averaged 11 (3-18). An improvement was reported in $63.4 \%$ of cases. Statistically significant decrease was found in the BASDAI score, visual analogue scale (VAS) for general health status as estimated by the patient and C-reactive Protein (CRP) $(p=0.001 ; p=0.01$ and $\mathrm{p}=0.03$; respectively).

There was no statistically significant difference between the efficacy of intra-articular glucocorticoid injection and sex, age, smoking, diagnosis and whether the hip involvement was bilateral or not $(p=0.5 ; p=0.2 ; p=0.8$ and $p=0.1 ; p=0.6$; respectively). Steroid injections were less effective in patients treated with biologics $(p=0.04)$. However, it was more effective in AS with early hip involvement $(\mathrm{p}=0.03)$.

Conclusion: Hip involvement is a negative prognostic factor in chronic inflammatory rheumatic diseases. Therefore, early diagnosis and management is essential in order to slow down the structural progression and the need for prosthetic surgery.

Disclosure of Interests: None declared

DOI: 10.1136/annrheumdis-2020-eular.6398

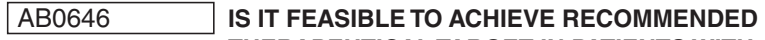 THERAPEUTICAL TARGET IN PATIENTS WITH AXIAL SPONDYLARTHRITIS IN CLINICAL PRACTICE? DATA FROM THE SPA-PAZ COHORT}

K. N. Franco Gomez ${ }^{1}$, C. Plasencia', M. Novella-Navarro',

D. Benavent ${ }^{1}$, P. Bogas ${ }^{1}$, R. Nieto ${ }^{1}$, I. Monjo ${ }^{1}$, L. Nuño ${ }^{1}$, A. Villalva ${ }^{1}$,

D. Peiteado ${ }^{1}$, A. Balsa ${ }^{1}$, V. Navarro-Compán ${ }^{1} .{ }^{1}$ University Hospital La Paz,

Rheumatology, Madrid, Spain

Background: Current ASAS/EULAR recommendations for the management of patients with axial spondylarthritis (axSpA) establish that the therapeutic goal to achieve in clinical practice is remission, defined as the absence of both clinical and laboratory disease activity evaluated by BASDAI\&CRP or preferably ASDAS and if this is not possible, low disease activity may be an alternative. Recently, ASDAS nomenclature has been modified, calling now low disease activity to what was previously called moderate activity. To this day we do not know if this target is feasible in clinical practice.

Objectives: To analyze the frequency of patients with axSpA achieving maintained remission $(\mathrm{R})$ or low disease activity (LDA) after receiving biological therapy. Secondary objectives included: i) to assess if the activity index used influences the frequency of maintained R/LDA, ii) analyze the prognostic factors for achieving maintained R/LDA.

Methods: An observational, longitudinal study of a prospective cohort (SpA$\mathrm{Paz}$ ) including all patients with axSpA who initiated their first biological treatment between the years 2003-2017. Demographic, clinical and analytical data were collected at the beginning of treatment and clinical disease activity measured by BASDAI\&CRP and ASDAS every 6 months for 2 years. Maintained R was defined as (BASDAl<2 \& normal CRP and/or ASDAS $<1.3$ ) and maintained LDA (BASDAI $<4$ \& normal CRP and/or ASDAS $<2.1$ ) on at least 3 consecutive visits. Statistical analysis: i) measures of central tendency and dispersion for quantitative variables and frequencies for qualitative variables; ii) univariate and multivariate analysis of binomial logistic regression model and calculation of $\mathrm{OR}$ and $95 \% \mathrm{Cl}$. 